\title{
AC 2012-3764: MULTI-DISCIPLINARY INTEGRATION FOR DESIGN AND CONSTRUCTION FRESHMAN: STRUCTURAL ORGANIZATION AND CHALLENGES
}

\section{Dr. Yilmaz Hatipkarasulu, University of Texas, San Antonio}

Yilmaz Hatipkarasulu holds M.S. and Ph.D. degrees in civil engineering from Louisiana State University. $\mathrm{He}$ is currently the Coordinator of the Construction Science and Management program at the University of Texas, San Antonio.

\section{Dr. Vincent B. Canizaro, University of Texas, San Antonio}

Vincent Canizaro is currently the Chair of the Department of Architecture at the University of Texas, San Antonio. A registered architect for 15 years, he has practiced in Texas, Massachusetts, and California. He has published Architectural Regionalism (Princeton Architectural Press, 2007), served on the Editorial Board for and published articles in the Journal of Architectural Education, contributed a chapter in Pragmatic Sustainability (Routledge, 2010), and given many presentations in areas of interest that include regionalism, place, pedagogy, community design, and sustainability.

\section{Dr. John D. Murphy Jr., University of Texas, San Antonio}

John D. Murphy holds a B.S. in building construction, a M.S. in construction management, and a Ph.D. in architecture from Texas A\&M University. He is currently the Dean of the College of Architecture at University of Texas, San Antonio. 


\title{
Multi-Disciplinary Integration for Design and Construction Freshman: Structural Organization and Challenges
}

\begin{abstract}
Professional degree programs, including design, architecture, engineering and construction, traditionally structure their curricula towards delivering the body of knowledge required by their professions. In the last decade, significant reductions in the credit hours available for discipline specific courses within respective curricula have forced the programs to eliminate a number of electives and multi-disciplinary opportunities. This created further segregation of the disciplines and disconnected a majority of the student groups even when they are within the same organizational unit. Considering the fact that the building construction projects include active and continuous collaboration of all of these parties, learning multi-disciplinary strategies is a necessary acumen with which students must graduate in preparation for professional practice. New technologies and project development approaches such as building information modeling is are necessitating early and extensive collaboration among the professions. Integrated project delivery methods are maximizing this need for interdisciplinary team production. Feedback from industry representatives and practicing professionals unanimously supports the concept of integration. This paper describes an effort to establish a multi-disciplinary first-year curriculum for design and construction freshman that includes content from three independently accredited programs. The curriculum is structured as a 28 -hour required coursework where more than half of the courses are discipline specific. The students are accepted to the university as pre-majors and asked to apply for a major at the completion of the required first year curriculum. As a part of their first year curriculum, the students are exposed to all professional career paths within the built environment disciplines and experience multi-disciplinary content. A detailed discussion of balancing the multi-disciplinary content, university core curriculum challenges, accreditation standard limitations, faculty preparation and assignment challenges, and establishing industry support are included in the paper. The paper also maps a goal of continuing collaboration approach within the disciplines by utilizing several multi-disciplinary courses in second through fourth year coursework.
\end{abstract}

\section{Introduction}

Professional degree programs, including design, architecture, engineering and construction, traditionally structure their curricula towards delivering the body of knowledge required by their professions. Requirements of professional practice, licensing, and accreditation shape the professional degree curriculums in addition to the academic and university definitions. In the last decade, significant reductions in the credit hours available for discipline specific courses within respective curricula have forced the programs to eliminate a number of electives and multidisciplinary opportunities. While it was possible to deliver 160 to 200 semester credit hours in a four-year degree program in the 1940s and 1950s, this number was reduced to 135 to 160 semester credit hours in the $1960 \mathrm{~s}$ and $1970 \mathrm{~s}^{1,2}$. This trend continued in the last decade to further pressure reductions in the professional degree programs. In some cases, this became a legal requirement mandated by state governments. For example, in 2005, the State of Texas revised their Education Code ${ }^{3}$, denoting that "to earn a baccalaureate degree, a student 
may not be required by a general academic teaching institution to complete more than the minimum number of semester credit hours required for the degree by the Southern Association of Colleges and Schools, or its successor, unless the institution determines that there is a compelling academic reason for requiring completion of additional semester credit hours for the degree." In this example, the target was simply set at 120 semester credit hours ${ }^{4}$. In most cases, the primary candidates for reduction were the multi-disciplinary / cross-disciplinary courses and elective options. This created further segregation of the disciplines and disconnected majority of the student groups even when they are within the same organizational unit.

Considering the fact that building construction projects include active and continuous collaboration of all of these parties, learning multi-disciplinary strategies is a necessary acumen with which students must graduate in preparation for professional practice. New technologies and project development approaches such as building information modeling are necessitating early and extensive collaboration among the professions. Integrated project delivery methods are maximizing this need for interdisciplinary team production. Feedback from industry representatives and practicing professionals unanimously supports the concept of integration.

This paper describes an effort to establish a multi-disciplinary first-year curriculum for design and construction freshman that includes content from three independently accredited programs. These include a Bachelor of Science degree in Architecture accredited by the National Architectural Accrediting Board ${ }^{5}$, a Bachelor of Science degree in Interior Design accredited by the Council for Interior Design Accreditation ${ }^{6}$, and a Bachelor of Science degree in Construction Science and Management, an accreditation candidate by the American Council for Construction Education ${ }^{7}$. A detailed discussion of balancing the multi-disciplinary content, university core curriculum challenges, accreditation standard limitations, faculty preparation and assignment challenges, and establishing industry support are included in the paper. The paper also maps a goal of continuing collaboration approach within the disciplines by utilizing several multidisciplinary courses in second through fourth year coursework.

\section{Historical Perspective on Built Environment Disciplines and Integration}

Curriculum integration is not a new concept that, by definition, assumes combining aggregated pieces into a functioning unit. There are several examples of integration efforts in engineering $8,9,10$ and construction disciplines ${ }^{11,12,13}$. Some of these efforts specifically focus on first-year curricula ${ }^{14,15}$ while others take a multi-disciplinary and holistic approach ${ }^{16,17,18,19,20}$. The extent of these efforts are very dependent on the discipline specific conditions where the integration may be structured around lecture or studio-based ${ }^{9,16}$ courses.

To increase the understanding of design and construction curriculum integration, it is important to note traditional educational approaches in these disciplines. Design disciplines, such as architecture and interior design, structure their curricula around studio-based teaching which are usually 4 to 6 semester credit hours and involve more contact. Such courses are typically projectbased within which a student is presented with a defined design project brief and is expected, with intense faculty guidance, to develop a design proposal. This approach is supported with a number of lecture-based technical and non-technical classes. On the other hand, construction curricula usually includes lecture and laboratory based courses that are typically designed as 3 
semester credit hours. Both disciplines emphasize industry feedback and professional practice concerns to be included in the curriculum ${ }^{21,22,23}$.

"Architecture Construction Alliance" $(\mathrm{A}+\mathrm{CA})$ leads the interdisciplinary collaboration efforts at an institutional level. $\mathrm{A}+\mathrm{CA}$ is a unique organization whose mission is " ... to foster collaboration among schools that are committed to fostering interdisciplinary educational and research efforts between the fields of architecture and construction, and to engage leading professionals and educators in support of these efforts ${ }^{24}$." The alliance recently conducted a short survey of member institutions to define (and benchmark) collaboration and integration among architecture and construction education disciplines. While the results of the survey were completely anecdotal, it can be said that many of the issues discussed in this paper were highlighted by the variance of open answers and indicated much residual opportunity for better collaboration of curricula. The members of the A+CA continue to discuss ways to better the effectiveness of pedagogical strategies to integrate what are usually considered very different education approaches.

\section{Multi-Disciplinary Structure for Design and Construction Freshman}

The College of Architecture at The University of Texas at San Antonio (UTSA) emerged out of the Division of Architecture which has its origins from within the College of Fine and Applied Arts began in 1979. This relatively young College (formally established in 2005), now offers architecture, interior design, and construction science and management degrees at the undergraduate level. These programs follow independent accreditation standards $5,6,7$. However, the graduates from these programs work in collaboration within the built environment, thus making the multi-disciplinary understanding a critical educational element.

In 2007 and 2008, the College of Architecture faculty created a common first-year curriculum for all students accepted into the college which was first implemented in the 2010-11 academic year. The first year curriculum consists of 28 credit hours of required coursework and is structured such that more than half of the courses are discipline specific. The remainder of the coursework includes core curriculum courses that are required of all students including courses in math, physics, and writing that are required of all UTSA students. The students are accepted to the university as pre-majors and asked to apply for a major at the completion of the required first year curriculum. As a part of their first year curriculum, the students are exposed to the professional career paths for architects, interior designer and construction managers all of which fall within the built environment disciplines and experience multi-disciplinary content. The 28hour required coursework includes:

- Core Curriculum

- MAT 1093 Precalculus

- PHY 1603, 1611 Physics I and Laboratory

- WRC 1013 Freshman Composition I

- WRC 1023 Freshman Composition II
- College of Architecture (COA)

- COA 1113 Intro to the Built Environment

- COA 1133 Building Technology I

- COA 1213 Design I

- COA 1223 Design II

○ COA 1313 Design Visualization

Figures 1, 2, and 3 illustrates the degree plans for Bachelor of Science in Architecture, Interior Design, and Construction Science and Management respectively. The common year is noted as the first block in each degree plan followed by the gateway into the discipline specific courses. 


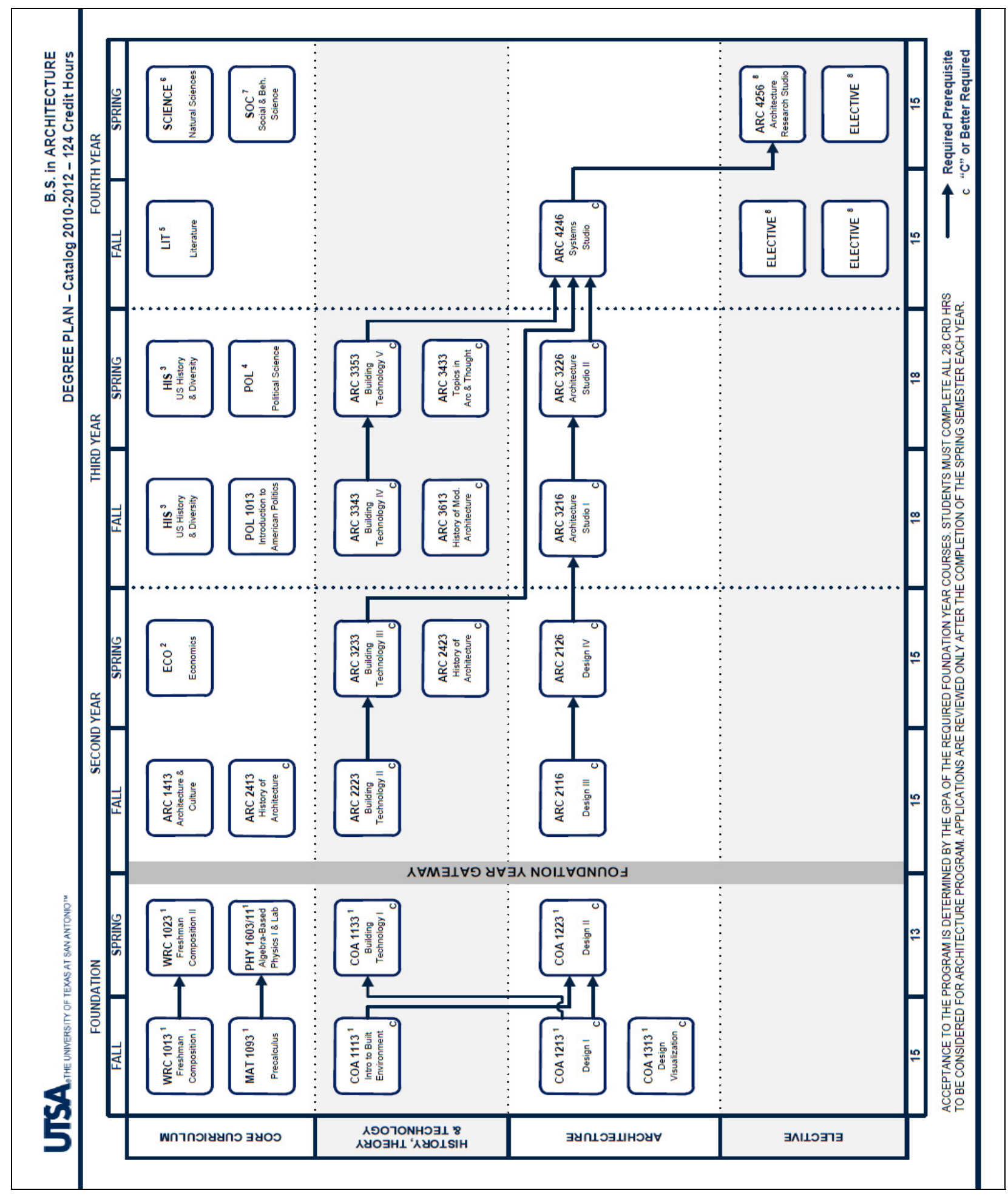

Figure 1. Bachelor of Science in Architecture Degree Plan 


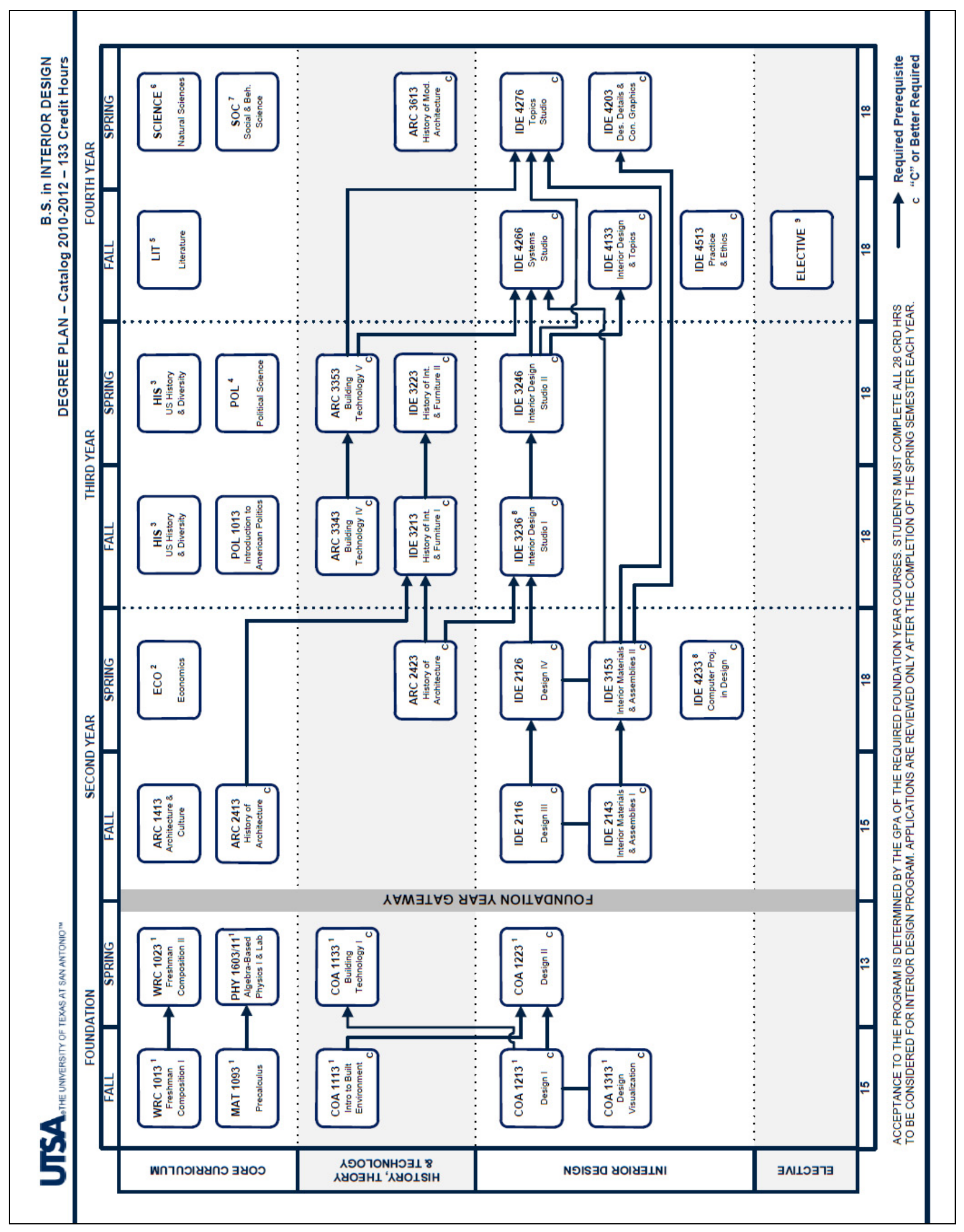

Figure 2. Bachelor of Science in Interior Design Degree Plan

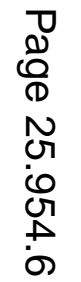




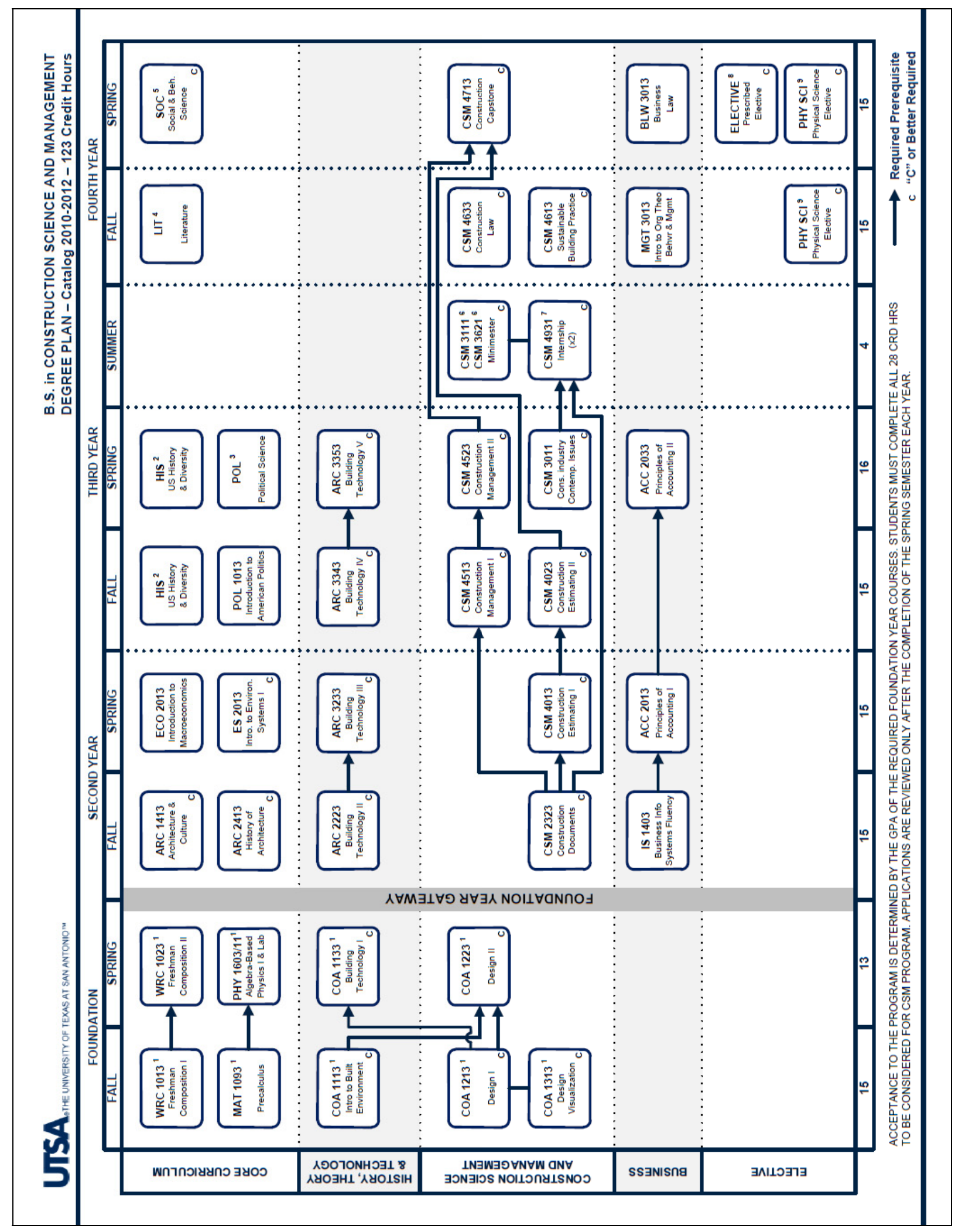

Figure 3. Bachelor of Science in Construction Science and Management Degree Plan 
As shown in Figures 1, 2, and 3, there were three important elements in creating this structure. The first element was to have a similar topical classification for the degree plans. All three degree plans categorize "core curriculum", "history, theory, and technology", and "electives" for each semester creating an organized and common structure. This similarity is important for planning purposes as well as establishing a tone of camaraderie among design and construction students. The second element was to establish a "College of Architecture" rubric to emphasize that the first year courses do not belong to any specific discipline but for all freshman in the college. These courses use "COA" prefix instead of "ARC", "IDE", or "CSM" in catalog listings. The use of "COA" prefix also minimizes questions from the faculty members about the intention of these courses, further emphasizing the concept of integration. The third element was to identify a path for further collaboration and integration. The courses under "history, theory, and technology" category establishes a common list in second and third years. Although the list is not identical for each degree plan, design and construction students share at least three other courses (two building technology courses and one history of architecture course) in addition to the common first year.

There is a "senior studio" or "capstone" listing in the last semester of each degree plan to serve as a project course where students demonstrate their understanding of the body of knowledge in each discipline. This creates an, as yet untested, opportunity to teach a comprehensive project class where architecture and interior design students perform the design tasks and construction students complete construction/preconstruction functions. However, this opportunity also has a number of challenges. The first challenge is to coordinate, with regard to scheduling, the performance and production of designers with construction students. The design, development, detailing and other preconstruction activities require an attention to detail in the academic setting such that design development often occupies the entire semester. During this time, the production of the construction students would be very limited. This suggests that this particular collaboration would require some form of sequential semester application. However, a possible opposite deficit for which one would have to guard is the potential of design students finding themselves to be less productive. A second challenge is the level of preparation for the participating students. The architecture program at UTSA is a 4+2 program where the first fouryear curriculum is "pre-professional" and considered as preparation for the 2-year Master of Architecture professional degree. Without the Master's, or other appropriate professional degree, a graduate is not able to sit for the architecture professional licensure exam. Our limited experience in this collaboration shows that preparation level of Master of Architecture students are is more appropriate for potential collaborative coursework with the construction and interior design undergraduate students.

Overall, the structure establishes a common first year with 28 credit hours of coursework for the freshman and creates multiple opportunities to collaborate in the following three years. Because of the prescribed list of courses, the common year also establishes a strong cohort that is expected to stay together through the rest of their specific academic coursework. However, by including a limited number of core curriculum courses within the common first year creates another problem for students who are accepted into the college with transfer credits either through advance placement tests or from their previous majors (for transfer or change-of-major students). Often these credit hours are core curriculum courses that make it difficult to maintain a 
full time schedule in the third and fourth years as students matriculate through upper division coursework.

\section{Multi-Disciplinary Content Management}

The management of the multi-disciplinary content is the most challenging aspect of the integration. In addition to defining the content, faculty preparation and delivery of the courses take center stage in establishing the multi-disciplinary attitude. The College of Architecture faculty have the primary responsibility in preparation and delivery of the following "COA" courses. As described in the 2008-2010 university catalog:

- COA 1113 Introduction to the Built Environment (3-0) 3 hours credit. Introduction to design and construction in the built environment through the concepts of place, context, ecology, space, analysis, aesthetics and research. Includes consideration of issues associated with the practice of architecture, interior design, landscape architecture, planning, urbanism and construction.

- COA 1133 Building Technology I - (3-0) 3 hours credit. Prerequisite: COA 1213. Introduction to concepts and skills fundamental to structure, construction, building enclosure, sustainability, and interior environments. Analysis and selection of materials, components, and assemblies. Introduction to the historical role of materials in architectural and interior design.

- COA 1213 Design I - (0-6) 3 hours credit. Prerequisite: Completion of or concurrent enrollment in COA 1313. Introduction to design through a focus on design literacy and the creative conceptualization of issues fundamental to the design of human environments.

- COA 1223 Design II - (0-6) 3 hours credit. Prerequisites: COA 1113, COA 1213, and COA 1313. Introduction to design as a broadly creative process based on the consideration of spatial experience, context, program and building form.

- COA 1313 Design Visualization - (0-6) 3 hours credit. Prerequisite: Completion of or concurrent enrollment in COA 1213. Introductory exploration of graphic processes and techniques utilized in the design and construction of the built environment for the representation, visualization, analysis, and presentation of the designed environment. Completion of or concurrent enrollment in this course is required in order to take COA 1213.

The first course listed above provides an introduction to three professions central to the built environment and requires a thorough understanding of the roles and responsibilities of each. Ideally the course would be team taught by representatives of each of the three disciplines (architecture, interior design and construction science and management). If this is not possible, as it has been for us thus far, it is extremely important for the instructor to have an unbiased and fair presentation of the disciplines. And since this course also provides an orientation for the freshman, it is important to evenly explain and manage student expectations for each degree 
program. Our experience has shown thus far that the introduction of the professions tends to gravitate toward the instructor's disciplinary background despite their best efforts resulting in a more biased presentation than desirable. In addition, another challenge to the single instructor model is knowledge and expertise. Rare is the individual faculty member who is adequately versed and experienced in all three disciplines. So again, we have surmised that the teamteaching option may provide a controlled balance for this course despite the potential managerial difficulties it may present structurally and with regard to the continuity throughout the semester.

The second course in the list is a "materials and methods" course that is essential for all built environment disciplines. It is perhaps the easiest integration opportunity because the course content is mutual and identical concern for each discipline. The list also includes two studio classes, Design I and Design II. These studio courses are the most difficult to modify due mostly to content but also instructional methodology. The content issue is that studios consist of experiences in the design of buildings and building interiors that develop and require skills (drawing, model-making, etc) that are not, at least at first glance, transferable to many of the organizational or business-oriented skills that are a part of construction. Thus, these studios tend to remain less than multi-disciplinary in a single course context, requiring that the multidisciplinary facets occur through the program of study as a whole. As such it is expected that these introductory design courses are delivered even though all students are not going to become designers. Therefore, those students pursuing the construction science and management degree, will, at a minimum, be exposed to some of the skills and concerns of designers. This has been a result that we are finding to be more useful than first appeared. In terms of methodology, these design studios are more amenable to multi-disciplinary content as they closely resemble lab courses used by a variety of other disciplines. However, as these courses and all of the instructors have architecture and interior design as their disciplinary background these courses present a set of unique challenges. Classes based in the Arts, as are both architecture and interior design, tend to measure success in both technical and expressive or creative achievement. As such, the instruction is also tied to the instructor's approach and attitude, which like student success is based in their own technical and expressive or creative competency. Simple additions to the course projects such as quantification of the materials used and recording of the time spend on each project stage (simplified versions of estimating and scheduling tasks) may provide opportunities to introduce subjects not typically included in design classes. The last course in the list, Design Visualization, introduces graphical and communication concepts and skills that are shared within the three disciplines, including various graphical presentations used in the design and construction of the built environment. So, similarly to the "materials and methods" course, the visualization content is essential for all disciplines and includes multi-disciplinary content.

There are two important issues related to the faculty expectations that must be noted as a part of the content management. The first one is related to the faculty's resistance to change. It is very critical to address the fact that while some of the courses may carry the same titles or similar content, with the integrated approach, they are no longer "construction only" or "design only" courses. Even though the deliberations for the development of the common first year create an environment of discussion and consensus, it is very likely to have faculty members that show resistance to adjusting the content and tone of their courses especially when they have been taught in a specific way for many years or fall back upon the assumptions that are a part of their own discipline. This is expected to be a larger challenge for institutions with high number of 
faculty members with long years of service. The second issue is the ownership of the common year. In our case, the foundation year was developed initially by design faculty and only edited by construction science faculty as the program was in its initial inception. While unique, it points to the need to remain vigilant of the disciplinary bias spoken of above. With regard to ownership, the scheduling, review and maintenance of the common year is considerable work that requires continuous attention. Since the idea of the integrated approach carries the discussion beyond the collaborating disciplines, handling the management and maintenance might be more appropriate at the college level with representation of each discipline. Although this operation will require resources that can be addressed easier at larger institutions, smaller institutions carry an advantage of having less compartmentalization.

\section{Summary and Conclusions}

As our experiences have shown, in the short time we have had the program in place, the goal of multi-disciplinary integration for design and construction freshman is a valuable and viable one. However, there are challenges that are both unique to each institution and structural based on the differences that remain between the design and construction industries. In practice, the three disciplines occupy the broader space of the built environment, but play different, yet related, roles in its development. And yet, some of these differences are temporal (that design tends to proceed construction), some of which are procedural (that designers and construction managers have different work flows and ways of working), and some are based simply on differing traditions that makes such integration a challenge.

We have seen, however, that such integration is not only possible, but, by and large positively pointing the way forward. Our program is in its infancy and will need adjustments as we monitor its successes and failures. But outside of the academic challenges, our shared professions are undergoing changes due to the advent and adoption of new technologies and project development approaches that are transforming our formerly more segregated practices into a more collaborative one. Integrated project delivery methods are maximizing this need for interdisciplinary team production and professional academic programs must rise to this challenge.

\section{References}

1. Burt R. A. and Hatipkarasulu Y. (2007) Evolution of Construction Education in the United States: A Case Study. Proceedings of the Construction and Building Research Conference of the Royal Institution of Chartered Surveyors, RICS COBRA 2007, Atlanta, GA.

2. Burt, R. A., Hatipkarasulu, Y., and Nobe, M.C. (2008) Evolution of Construction Education in the United States: Two Case Studies. Proceedings of the Associated Schools of Construction 2008 Annual Conference, Auburn, AL.

3. TEC (2005). Semester Credit Hours Required for Baccalaureate Degree. Texas Education Code $\S 61.0515$. Added by Acts 2005, 79th Leg., ch. 1230, § 12, eff. June 18. 
4. SACS (2007). Principles of Accreditation: Foundations for Quality Enhancement. The Commission on Colleges of the Southern Association of Colleges and Schools, 2007, Decatur, GA.

5. NAAB (2011). National Architectural Accrediting Board Procedures for Accreditation." National Architectural Accrediting Board, Washington DC.

6. CIDA (2009). Council for Interior Design Accreditation Policy and Procedures. Council for Interior Design Accreditation. Grand Rapids, MI

7. ACCE (2010). Standards and Criteria for Baccalaureate and Associate Programs. American Council for Construction Education, San Antonio, TX.

8. Nelson, J.D., and Schröder, B. (2001) Establishing an Integrated Mathematics, Engineering, and Science Curriculum: Lessons Learned. Proceedings of the 2001 American Society for Engineering Education Annual Conference \& Exposition, Albuquerque, NM

9. Kellam, N., Walther, J., Costantino, T., and Cramond, B. (2010) Integrating The Engineering Curriculum Through Crossdisciplinary Studios. Proceedings of the 2010 American Society for Engineering Education Annual Conference \& Exposition, Louisville, KY.

10. Froyd, J.E. and Ohland, M.W. (2005). Integrated Engineering Curricula. Journal of Engineering Education, 2005. 94(1): p. 147-164.

11. Martin-K., Giselle O., Feige, D. M., and Soodak, L. C. (1995). Curriculum Integration: An Expanded View of an Abused Idea. Journal of Curriculum and Supervision, 10, 227-249.

12. Mills, T.H., Auchey, F.L., and Beliveau, Y.J. (1996) The Development of a Vertically and Horizontally Integrated Undergraduate Building Construction Curriculum for the Twenty First Century. Journal of Construction Education, Summer 1996, 1(1) pp. 34 - 44

13. Hauck, A.J. (1998) Construction Management Curriculum Reform and Integration with a Broader Discipline: A Case Study Journal of Construction Education, Summer 1998, 3(2) pp. 118-130

14. Al-Holou, N, Corleto, C., Demel, J., Froyd, J., Hoit, M., Morgan, J., and Wells, D. (1998), First-Year Integrated Curricula Across Engineering Education Coalitions, 1998 Frontiers in Education Conference, Tempe, AZ.

15. Yost, S. A. and Hoback, A. S. (2000) A team approach to interdisciplinary instruction in a first-year engineering design course. American Society for Engineering Education North Central Section Spring Conference Proceedings, Lansing, MI, Mar 2000.

16. Costantino, T., Kellam, N., Cramond, B., and Crowder, I., (2010) An Interdisciplinary Design Studio: How Can Art and Engineering Collaborate to Increase Students' Creativity? Art Education, 63(2): p. 49-53.

17. Yost, S., Krishnan, M., and Paulik, M. (2008) Development Of An Integrated Spiral Curriculum In Electrical And Computer Engineering. Proceedings of the 2008 American Society for Engineering Education Annual Conference \& Exposition, Pittsburg, PA.

18. Collura, M., Daniels, S., and Nocito-Gobel, J. (2007) The current generation of integrated engineering curriculum - assessment after two years of implementation. Proceedings of the 2007 American Society for Engineering Education Annual Conference \& Exposition, Honolulu, HI.

19. Hauck, A.J., and Jackson, B.J. (2005). Design and Implementation of an Integrated Construction Management Curriculum. Proceedings of the Associated Schools of Construction 2005 Annual Conference, Cincinnati, OH. 
20. Montoya, M. A, Kelting, S.C. and Hauck, A.J. (2009) Pilot Study of an Integrated Construction Management Curriculum. Proceedings of the Associated Schools of Construction 2009 International Conference, Gainesville, FL.

21. Becker, T.C., Jaselskis, E. J., and McDermott, C. P. (2011) Implications of Construction Industry Trends on the Educational Requirements for Future Construction Professionals. Proceedings of the Associated Schools of Construction 2011 International Conference, Omaha, NE.

22. Olsen, D. A. and Burt, R. A. (2010). The "Chip Voting System": Bridging the Gap Between Industry and Faculty During a Curriculum Revision. Proceedings of the Associated Schools of Construction 2010 International Conference, Boston, MA.

23. Lee, N., Ponton, R., Jeffreys, A.W., and Cohn, R. (2011) Analysis of Industry Trends for Improving Undergraduate Curriculum in Construction Management Education. Proceedings of the Associated Schools of Construction 2011 International Conference, Omaha, NE.

24. ACA (2012). Architecture and Construction Alliance. Information available at http://aplusca.info/ 